\title{
Paradigmas teóricos sobre a performance musical na cultura popular
}

\author{
Fábio Henrique Gomes Ribeiro (Universidade Federal da Paraíba, João Pessoa, Paraíba, Brasil)
}

fabiomusica_fe@yahoo.com.br

\begin{abstract}
Resumo: Este artigo discute algumas dimensões epistemológicas sobre performance musical articulando perspectivas dos estudos da performance e da etnomusicologia. Para isso, tomo como base uma vasta pesquisa bibliográfica nesses campos, reunindo perspectivas teóricas e abordagens etnográficas a partir de uma revisão bibliográfica de estudos etnomusicológicos brasileiros sobre cultura popular. Os resultados destacam um contexto epistemológico bem definido, envolvendo três abordagens teóricas recorrentes para compreender as práticas musicais da cultura popular (performance reflexiva, generativa e de resistência). Com isso, defendo que as bases epistemológicas dos estudos da performance têm orientado as perspectivas teórico-metodológicas e gerado paradigmas etnomusicológicos sobre a performance musical na cultura popular.

Palavras-chave: Performance musical; Paradigmas teóricos; Cultura popular.
\end{abstract}

Theoretical paradigms on musical performance in popular culture

Abstract: This paper discusses some epistemological features on music performance and articulates the perspectives on performance studies and on ethnomusicology. It is based on ethnographic research in these fields, bringing together theoretical and ethnographic perspectives through a bibliographical review on Brazilian ethnomusicological studies about traditional culture. The results highlight a well-outlined epistemological context with three theoretical approaches about musical practices of traditional culture (reflexive, generative and resistance performance). So, I defend that more general epistemological basis on performance studies has guided the theoretical-methodological perspectives and generated ethnomusicological paradigms on the music performance in the popular culture.

Keywords: Music performance; Theoretical paradigms; Traditional culture.

\section{Introdução}

Performance é um tema recorrente em estudos sobre fenômenos musicais brasileiros, sobretudo no campo da etnomusicologia. Entretanto, devido à sua forte proximidade com definições do senso comum e às necessidades idiossincráticas de cada contexto estudado, a forma como o termo se apresenta na literatura ainda não é compreendida de forma ampla e sistemática. A performance tem sido pensada tanto de forma superficial, como desempenho musical, quanto de forma bastante aprofundada a partir da realidade prática e conceitual de cada comunidade de prática musical.

Esse balanço entre superficialidade e profundidade representa correntes de pensamento que podem nos ajudar a entender melhor como temos produzido conhecimento sobre a performance musical. Buscando apresentar contribuições nessa direção, este texto discute algumas dimensões epistemológicas sobre a performance musical articulando as perspectivas dos estudos da performance e do campo da etnomusicologia, especialmente em estudos sobre práticas musicais da cultura popular.

Os resultados e reflexões são parte de um conjunto de pesquisas realizadas com grupos de cultura popular nos últimos oito anos (RIBEIRO, 2011, 2017b) e de uma vasta pesquisa bibliográfica nos campos dos estudos da performance e da etnomusicologia. Além disso, o texto tem como base metodológica fundamental a articulação de perspectivas teóricas e abordagens etnográficas a partir de uma revisão bibliográfica de teses e dissertações sobre cultura popular no campo da etnomusicologia. A revisão foi conduzida no intuito de reunir, de forma sistematizada, os resultados e reflexões de pesquisa sobre performance musical na cultura popular.

Buscando compreender as relações entre um contexto teórico mais amplo e os estudos etnográficos analisados, o texto apresenta uma estrutura que acredito ser suficiente 
para a proposta apresentada. Assim, discuto as principais características dos estudos da performance, as abordagens etnomusicológicas mais evidentes na literatura sobre a performance musical e as perspectivas teóricas presentes nos estudos sobre a cultura popular colocados em análise. Como considerações finais, eu apresento algumas perspectivas que entendo como caracterizadoras de paradigmas etnomusicológicos sobre a performance musical na cultura popular.

\section{Os estudos da performance}

O interesse pelas diversas formas expressivas do homem é algo presente há bastante tempo nas investigações das ciências humanas. Entretanto, a partir da chamada virada pós-moderna no campo da antropologia nos anos 1980, novas linhas investigativas sobre as formas expressivas começaram a se evidenciar de forma bastante significativa (FERREIRA, 2012; LUCAS, 2005). Tratam-se dos estudos da performance, que já vinham se desenvolvendo desde os anos 1960 em universidades norte-americanas, principalmente por meio das colaborações entre Richard Schechner, teatrólogo que se aproximou da antropologia, e Victor Turner, antropólogo que se juntou aos estudos do teatro.

As mudanças de perspectivas sobre fenômenos socioculturais e assuntos pouco investigados são representativas de redirecionamentos presentes em vários campos da ciência na pós-modernidade. O reconhecimento de que o saber científico está presente nos mais variados campos e não apenas naqueles reconhecidos e validados por uma perspectiva positivista de pesquisa compartimentada em campos estanques é um indício de que os olhares investigativos deveriam se voltar para fenômenos sociais menos privilegiados, cujo discurso fora muitas vezes negado no âmbito acadêmico. Assim, desenvolveram-se novos paradigmas em vários campos das ciências, constituindo-se em viradas sociológicas, linguísticas, filosóficas, históricas etc.

Nossa realidade passou a ser percebida como algo construído a partir de uma rede interativa complexa, composta por várias dimensões e relações simbólicas. Nesse sentido, nenhum objeto científico é dado pela natureza ou pelas estruturas sociais de forma restrita e completa, mas é algo construído a partir de várias relações entre as pessoas, seus contextos, situações, normas de conduta, concepções individuais e coletivas etc.

A partir desse panorama sumarizado, destaco as principais bases de desenvolvimento, as dimensões epistemológicas e o estado da arte nos estudos da performance, direcionando-me por três pressupostos: 1) os estudos da performance se desenvolvem a partir da interação entre as ciências sociais (principalmente antropologia e sociologia), a filosofia da linguagem e as artes performáticas; 2) além das relações com tais áreas específicas, há conexões com campos interdisciplinares mais amplos da teoria crítica contemporânea, como os estudos culturais e pós-coloniais; e 3) os estudos da performance se desenvolveram com uma característica fortemente transdisciplinar, alcançando atualmente variados campos investigativos que englobam dramas sociais, relações de gênero, práticas artísticas locais e globalizadas, espetáculos, identidades nacionais, política etc.

Há na literatura um conjunto de trabalhos importantes para o desenvolvimento do campo de estudos da performance que sinalizam algumas abordagens epistemológicas (sociológica, antropológica e linguística) e metodológicas (contextuais, comportamentais e estruturais) da performance. Aqui, diante da natureza transdisciplinar do campo, apresento uma perspectiva histórica, conceitual e epistemológica a partir das orientações sociológicas, linguísticas e antropológicas da performance.

O modelo sociológico de performance encontra suas bases iniciais mais estabele- 
cidas no trabalho de Erving Goffman em sua teoria sobre representação de papeis sociais em The presentation of self in everyday life (GOFFMAN, 1990), trabalho cuja primeira publicação foi em 1959. Na perspectiva de Goffman (1990), baseada em um paradigma teatral, toda atividade de um indivíduo em momento de interação com um ou mais observadores é entendida como performance. Assim, o mundo social é entendido como um palco no qual os indivíduos promovem interações face-a-face, desempenhando papéis socialmente preestabelecidos.

As orientações sociológicas para a performance desenvolvidas a partir de Goffman (1990) se aproximam das perspectivas de Hymes (1975), focando na relação entre o performer e audiência, constituindo-se a partir de um indivíduo que assume um papel diante de uma comunidade. Apesar do trabalho de Goffman (1990) evidenciar a responsabilidade de agenciamento do performer e ainda transparecer uma perspectiva de que as ações socioperformáticas do indivíduo podem não ser conscientes, há um destaque à interação entre performer e audiência como essencial. As formas de interação, portanto, caracterizam a performance, diferenciando-a do mero comportamento. Essa diferenciação é bem definida por Carlson (2010) ao analisar a obra de Goffman, destacando a "seleção de um 'front' (cenário, figurino, gestos, voz, aparência etc.) e o compromisso com a coerência e a organização seletiva do material apresentado, ambos exigidos pela direção da atividade direcionada à comunicação, e não às tarefas de trabalho" (CARLSON, 2010, p. 53).

Essa perspectiva interativa de performance se aliou à corrente do construcionismo social, com maior crescimento a partir da década de 1960 com as teorias de Berger e Luckmann (1991). Sumariamente, a perspectiva do construcionismo social entende a relação entre o homem e o mundo social como dialética, com atuação recíproca de um sobre o outro. Nesse contexto, a performance é compreendida como constantemente e interativamente construída, sem uma prescrição social, cultural ou natural dada e cristalizada.

Assim, as perspectivas das ações humanas em situações de interação social representam uma noção de performance mais ampla, levando em consideração situações que não estão necessariamente em clara evidência, como em um palco. Entretanto, para que algo seja compreendido como performance seria necessária uma estrutura básica de reconhecimento, que pode ser resumida aqui como frame, termo utilizado por Goffman (1990) para definir o processo de emolduração social realizado pelos indivíduos em momentos de interação.

Enfim, uma abordagem sociointerativa da performance leva em consideração as suas dimensões micro e macrossociais, percebendo os indivíduos como capazes de exercer múltiplos papéis e em constante diálogo com os aspectos mais amplos de suas comunidades. Por meio dessa abordagem, uma investigação sobre performance busca compreender como os indivíduos constroem suas relações e práticas performáticas a partir de suas formas de emolduração e interação social.

As orientações linguísticas sobre performance encontram suas bases em campos diversificados, com destaque para as abordagens antropológicas, sociocomunicativas e filosóficas sobre as formas verbais expressivas. Como as abordagens da antropologia linguística e as sociocomunicativas são bastante próximas, com um período de distanciamento entre os anos 1960 e 1980 e uma reaproximação após esse período (BAUMAN; BRIGGS, 2006), elas serão tratadas aqui de forma unificada, sob o termo "sociocomunicativo", que representa a busca por compreender a realização da vida social através do uso da língua.

$\mathrm{O}$ alicerce sociocomunicativo mais difundido é encontrado em um dos trabalhos mais conhecidos de Richard Bauman, Arte verbal como performance (BAUMAN, 1975). Assim como outros estudiosos do folclore norte-americano, como Abrahams (2011) e Briggs, 
com quem trabalhou junto (BAUMAN; BRIGGS, 2006), Bauman apresenta uma perspectiva focada em culturas expressivas entendidas como tradicionais, buscando compreender a comunicação como algo que tanto se constitui socialmente quanto constrói a sociedade. A partir desse posicionamento, Bauman $(1975,1992)$ entende que o estudo das formas verbais têm como tarefa descobrir os processos comunicativos a partir dos padrões, funções e significados sociais de suas práticas.

Tomando como base a concepção de performance como um evento comunicativo, Bauman (1975) destaca a dominância de sua função expressiva, tomando como foco os modos como a mensagem é comunicada. Langdon (2007), ao discutir tais perspectivas de Bauman, aponta que "os estudos desta abordagem dirigem seu interesse para como performances são construídas pelos participantes do evento, examinando o evento artístico (a situação de performance) e o ato artístico (a realização do evento por parte do(s) performer(s))" (LANGDON, 2007, p. 9). Assim, essa abordagem compreende as formas de performance como componentes sociais com significativo grau de publicidade, de valorização e de memorização de repertórios verbais, caracterizando-as como focos de atenção analítica para a etnografia da fala e da antropologia linguística (BAUMAN, 2014).

As abordagens filosóficas sobre as formas verbais expressivas encontram seu aporte teórico inicial e fundamental no trabalho de John Langshaw Austin sobre sua teoria dos atos de fala (AUSTIN, 1975). Austin (1975) se preocupou com tipos específicos de enunciados verbais, que atuam sobre a realidade, caracterizando-se como algo além de descritores sociais. Alguns exemplos dessa perspectiva são apresentados por Borba (2014):

Enunciados como 'Eu vos declaro marido e mulher', 'Batizo este navio Rainha Elizabeth II', 'Prometo que farei isso logo', 'aposto que vai chover amanhã', para Austin, não descrevem nenhum fato exterior à linguagem; são a ação em si, não havendo distinção entre dizer e fazer, pois proferir tais enunciados é em si agir (BORBA, 2014, p. 461).

Tais tipos de enunciados, ou atos de fala, passaram a ser definidos por Austin (1975) como performativos. O conceito deriva do termo inglês perform, verbo que se vincula a alguma ação, levando a pensar determinados tipos de enunciados como tal (AUSTIN, 1975). Nesse contexto, os enunciados passam a ser estudados em função de suas características de performatividade, ou seja, por sua capacidade de ação.

As reflexões contemporâneas sobre os atos de fala redirecionam o olhar investigativo dos enunciados performativos para a noção de performatividade de identidades sociais, tendo como fonte mais recorrente as perspectivas da filósofa Judith Butler, que, segundo Borba (2014), desenvolveu sua teoria nas complexas indefinições do que seria um enunciado constatativo ou performativo. Por meio da teoria de Butler (2011, 2013), que tem como principal foco as construções sociais sobre o gênero, enunciados que antes seriam compreendidos como meros descritivos passariam a ser percebidos também como agentes. Nesta perspectiva, dizer a uma criança que ela "é um menino" se caracteriza como uma ação de inserção do indivíduo em um conjunto de normas sociais ligadas às definições de gênero (BORBA, 2014).

Outra contribuição para as discussões sobre performance no plano das oralidades pode ser encontrada nos trabalhos do medievalista, historiador e linguista Paul Zumthor. Apesar da referência superficial dada a ele em estudos sobre performance, com sua noção de comunicação oral, com uma dimensão histórica que é incorporada no processo de performance e recepção, Zumthor (2007) apresenta uma significativa contribuição para se refletir sobre as dimensões comunicativas da performance. De acordo com a análise de Pimen- 
tel e Fares (2014) a respeito das perspectivas de Zumthor sobre performance, a importância dada por ele igualitariamente ao autor e ao leitor de obras literárias apresenta novas perspectivas para os sistemas literários, nos quais o texto só ganha vida na performance oral e incorporada.

Assim, uma abordagem linguisticamente orientada da performance nos leva a compreendê-la como ato comunicativo de caráter tanto reflexivo quanto generativo. As práticas performáticas podem, portanto, ser compreendidas a partir das formas pelas quais os indivíduos constroem, valorizam, tornam públicas, percebem, recebem e retribuem as ações comunicativas.

As orientações antropológicas sobre performance podem ser pensadas à luz das perspectivas simbólico-interpretativas. Durante o desenvolvimento inicial de uma antropologia interpretativa, que se tornou mais sólida e difundida a partir de Geertz $(1973,2008)$, os estudos sobre cultura encontram uma relação com a performance nos trabalhos de Milton Singer, que cunhou o termo performance cultural (SINGER, 1959). A partir de uma perspectiva transcultural e comparativa, Singer (1959) buscou compreender as culturas por meio de seus produtos culturais, bem como as formas pelas quais o homem a experimenta e percebe sua estrutura e suas contradições. Assim, a perspectiva de performance de Singer (1959) como algo mais ou menos claramente definível em tempo e espaço tem se tornado frequente nos estudos que a relacionam com a cultura.

Hymes (1975), a partir de uma perspectiva simbólico-comunicativa dentro dos estudos do folclore, também contribui para a definição conceitual de performance contrastando-a com as atividades do comportamento e da conduta. Carlson (2010) analisa as definições de Hymes (1975) e conclui que suas categorias são definidas a partir de relações de especificidade, estando uma categoria dentro da outra. Assim, a categoria do comportamento é mais ampla e engloba todo tipo de ação; a conduta é uma subcategoria, na qual os comportamentos seguem um conjunto de normas culturalmente definidas; e a performance é apresentada como um tipo específico de conduta na qual uma ou mais pessoas assumem uma responsabilidade frente a uma comunidade. A especificidade da performance se dá, segundo Hymes (1975), por ser uma conduta compreendida como interpretável, descritível e repetível.

Segundo Carlson (2010), os posicionamentos de Singer (1959) e Hymes (1975) são representativos de uma perspectiva de performance como uma atividade colocada à parte, enquanto Victor Turner busca compreendê-la a partir de suas ideias sobre liminaridade, como margem ou transição. Assim, Turner (2009) apresenta duas mudanças de perspectiva na teoria antropológica, sendo uma que muda o olhar da estrutura para o processo, e a outra, da competência para a performance, compreendendo grandes gêneros, como rituais, carnavais, dramas e espetáculos, ou, como destacou Royce (2004), como "texto no contexto".

Turner se tornou um dos principais representantes de uma perspectiva ritual sobre performance, embasando suas teorias a partir de uma antropologia da experiência, que se desenvolveu para uma antropologia da performance (TURNER, 1988, 1996, 2005), exercendo forte influência nos estudos sobre o tema baseados em uma antropologia simbólica e comparativa. Turner (1996), ao buscar compreender a dimensão simbólica das experiências humanas em ação, estabeleceu uma abordagem por ele nomeada de simbologia comparativa, que estaria entre a antropologia simbólica e a semiótica. A simbologia comparativa seria, dessa forma, mais limitada do que a semiótica, pois não buscava uma teoria geral de signos e símbolos; e mais ampla do que a antropologia simbólica, por se propor a ir além dos materiais etnográficos, buscando lidar com gêneros simbólicos das sociedades chamadas por ele de avançadas, complexas ou industriais de larga-escala. 
Nesse escopo da simbologia comparativa, Turner estabeleceu parte de suas contribuições reflexivas para o trabalho com o ritual e, consequentemente, com performance, traçando dimensões teóricas e metodológicas no que diz respeito aos seus conhecidos temas, como dramas sociais, ritos de passagem, liminaridade e comunitas. Todos esses temas são trabalhados com base na comparação entre as chamadas sociedades tradicionais e as industriais de larga-escala a partir de três variáveis conceituais importantes, a saber: o trabalho, o play [jogo ou brincadeira] e o ócio (TURNER, 1996). Cada sociedade teria, então, suas próprias formas de articular tais variáveis, constituindo-se ou como representativa daquelas entendidas como tradicionais ou como complexas de larga-escala.

A perspectiva antropológica da performance, desenvolvida em função das novas configurações da sociedade contemporânea multifacetada, aponta para a necessidade de se compreender e chamar a atenção para elementos marginais, arredios ou liminares focando os momentos de suspensão da vida cotidiana, tratando, essencialmente da relação entre cultura, sociedade e práticas performáticas (DAWSEY, 2005, 2006, 2007; LANGDON, 2007). Assim, podemos passar da compreensão sociológica de Goffman (1990) de performance como representação de papéis sociais na vida cotidiana para concebê-la como uma representação dessas representações - como um metateatro da vida, como defendeu Turner (1996) ou, para além disso, como um elemento ativo na vida social dos performers.

Desse modo, as orientações antropológicas da performance tencionam olhar para as dimensões simbólicas das práticas expressivas da cultura, principalmente em momentos de suspensão da vida cotidiana, espaços temporais nos quais as sociedades podem evidenciar de forma mais clara suas estruturas e significados.

As orientações artísticas sobre a performance demonstram que as artes não serviram unicamente como lentes analíticas transpostas para outras áreas, mas também produziram outros olhares sobre si mesmas. As dimensões performáticas influenciaram até mesmo os trabalhos no campo das artes visuais/plásticas, estáticas a priori no senso comum, apresentando-nos conceitos e posicionamentos artísticos como o happening, body art, body works, life art etc.

As ideias vanguardistas e experimentais dos artistas a partir dos anos 1960 proporcionaram um conjunto de questionamentos e reorientações conceituais, aproximando as artes da vida cotidiana, bem como das suas caracteríticas modernas, dos seus questionamentos existenciais e das suas múltiplas formas de interação multimidiáticas. Assim, a integração entre as artes, o reconhecimento de suas relações com os contextos sociopolíticos e a busca por explorar novas formas de expressão artística se tornaram meios de produção de novas perspectivas sobre performance (CARLSON, 2010).

Nesse contexto, destaco que as influências do teatro sobre as perspectivas inovadoras nas outras artes é bastante presente, o que nos ajuda a compreender porque é maior a produção acadêmica deste campo sobre performance. $\mathrm{O}$ teatro apresentou os principais paradigmas analíticos da performance nas teorias desenvolvidas nas fases seminais dos estudos até aqui apresentados. As perspectivas teatrais mais recorrentes na literatura da performance foram produzidas a partir dos trabalhos do teatrólogo Richard Schecner, que se interessou pelo modelo de drama social de Turner, discutindo formas de aproximação com o drama estético e, consequentemente, unindo as perspectivas antropológicas aos estudos do teatro, visando compreender, principalmente, as relações entre audiência e performer. Silva (2005) destaca o empenho de Schechner em demonstrar que entre ritual e teatro não há distinções, unificando-os sob o conceito de performance. Assim, os paradigmas do teatro auxiliaram também o desenvolvimento de uma antropologia das formas expressivas, ligando ritual, performance e drama. No continuum entre teatro e ritual ou entre drama estético e 
drama ritual, as teorias de Turner (1996, 2005; 2009) e de Schechner (1989, 1995, 2003, 2006; Schechener et al., 2013) colaboram para a construção de uma ideia de performance que vai além da representação de papéis sociais.

\section{A música em performance: algumas abordagens etnomusicológicas}

As formas de conhecimento desenvolvidas a partir das correntes epistemológicas destacadas aqui, dentre outras não citadas, mas de igual importância, contribuíram para o fortalecimento de perspectivas transdisciplinares sobre os fenômenos e expressões humanas. A música, nesse contexto, passou também a ser percebida de forma mais ampla e seu estudo sofreu fortes influências das mudanças paradigmáticas de vários campos investigativos. Blau (2009) apresenta um exemplo significativo ao destacar o artigo Paradigm for performance studies, de Pelias e Van Oosting, como uma produção representativa das mudanças paradigmáticas que alcançaram os estudos da música. Assim, o destaque das categorias de performance baseadas no texto, performer, audiência e evento representaram novos olhares para aspectos contextuais da prática musical.

Reconheço que o reposicionamento da música como objeto analítico não se deu em função de apenas uma influência direta, uma vez que tais mudanças são resultantes de reflexões epistemológicas mais amplas. Entretanto, compreendo que o processo de institucionalização da etnomusicologia e do consequente crescimento e fortalecimento de suas abordagens favoreceu de forma significativa o desenvolvimento das perspectivas mais amplas e mais próximas aos estudos da performance. A partir de processos investigativos que têm lidado mais comumente com música não notada (BÉHAGUE, 1984), a etnomusicologia tem se aproximado do homem como agente e produtor/criador de música - music-maker - (BLACKING, 1979), reconhecendo o valor das produções musicais em performance. A performance seria, então, um momento específico e mais ou menos bem definido na sociedade, que nos possibilita refletir de forma significativa sobre a produção musical de determinado grupo, bem como sobre sua vida sociocultural mais ampla.

Uma das mais influentes escolas etnomusicológicas sobre performance teve seu início na Universidade do Texas, em Austin, Estados Unidos, partindo dos estudos sobre folclore, baseados em perspectivas linguísticas, sociológicas e antropológicas. Nesse contexto, os trabalhos de Bauman (1975), Abrahams (2011), Américo Paredes (BUCHANAN, 2014; MORÍN, 2006) e da família Lomax (BUCHANAN, 2014) foram fundamentais para o desenvolvimento de uma perspectiva sobre o conhecimento musical em performance, em seu lócus de vida e em sua práxis cotidiana. A partir desse contexto e de suas múltiplas influências, Béhague (1984) desenvolveu suas teorias sobre performance e suas formas de participação na organização da vida social.

Assim, segundo Buchanan (2014), a gênese da teoria da performance musical na etnomusicologia se deu a partir da articulação das ideias dos folcloristas da Escola do Texas, em consonância com as teorias antropológicas de Turner (1988, 1996, 2005) e sociológicas de Goffman (1990), com significativas contribuições teóricas presentes nos trabalhos de Béhague (1984), Feld (2012) e Seeger (2015), mudando as lentes analíticas do texto para o contexto. A performance musical, nessa conjuntura, é compreendida a partir das constantes relações tanto reflexivas quanto generativas da vida social.

Apesar da aparente multiplicidade teórica sobre performance no campo da etnomusicologia, destaco aqui as perspectivas de três autores como principais norteadoras dos direcionamentos epistêmico-metodológicos em trabalhos etnográficos baseados na performance musical, principalmente em contextos latino-americanos. Béhague (1984), Seeger 
(2015) e Turino (2008a, 2008b, 2010) são defendidos aqui como os principais responsáveis pelo desenvolvimento de um olhar etnográfico baseado nas múltiplas relações contextuais da performance musical.

A atuação de Gehard Béhague pode ser resumida a partir das perspectivas de Volpe (2010), que destaca sua busca pela integração entre a musicologia histórica e a etnomusicologia, principalmente a partir de sua atuação como pesquisador de manifestações musicais da América Latina. Nesse contexto, suas perspectivas sobre performance tomaram a direção de uma redefinição conceitual. O termo performance practice, até então comumente associado à reconstrução dos períodos, gêneros e práticas musicais da música europeia passou a ser questionado e repensado em função do seu desligamento de questões sobre os contextos, eventos e graus de aceitação da performance (BÉHAGUE, 1984; HERNDON, 1986).

Na obra bastante referenciada de Béhague, Performance practice (BÉHAGUE, 1984), composta por um conjunto de cinco ensaios, com a participação de mais quatro autores, há significativos exemplos de suas perspectivas sobre a integração entre som e contexto na composição da performance musical. Essa integração é discutida em vários direcionamentos, como na relação entre performers e audiência, na composição de grupos musicais, nas habilidades de improvisação, nas mudanças de forma e conteúdo das práticas musicais, nos estilos de repertórios, características sociomusicais de performers e relações entre ações individuais e contextos rituais preestabelecidos, entre outros aspectos.

As perspectivas de Béhague têm influenciado fortemente os trabalhos etnomusicológicos brasileiros, entretanto, com uma ressalva cada vez mais recorrente sobre seu posicionamento a respeito dos aspectos distintivos em relação à dimensão estética e acústica da prática musical. Seu posicionamento de que a integração entre som e contexto é definido como reunião entre elementos musicais e "extramusicais" tem sido rediscutido. Diante da perspectiva cada vez mais ampla do significado de música, a literatura tem definido um posicionamento diferenciado, destacando que os elementos sonoros, visuais, comportamentais e simbólicos, entre outros, também são entendidos como musicais.

Seeger (2015), ao estudar a música dos Índios Suyá [hoje, Kisêdjê], enfatizou a distinção entre antropologia musical e antropologia da música, defendendo a utilização da primeira e destacando o estudo de uma sociedade a partir das perspectivas da performance musical. Ao centrar seu estudo na performance, Seeger (2015) aproxima suas perspectivas das de Béhague (1984), ao compreendê-la como processo social. Essa proximidade foi reconhecida por Béhague em análise do trabalho de seu par, apontando ainda que a concentração sobre performance como algo que envolve emoções, intenções, realizações, formas e estruturas proporciona a superação dos paradigmas funcionalistas de Merriam (1964) na direção de uma compreensão mais holística e dinâmica dos fatores musicais da vida social (BÉHAGUE, 1988, p. 261).

O trabalho de Seeger (2015) tem sido base para um conjunto de outras atividades investigativas voltadas tanto para comunidades indígenas quanto para outros contextos. Sua etnografia baseada em perguntas que ele chamou de questões jornalísticas básicas (o quê? quem? como? onde? quando? para quem? e porque?) nos apresenta direcionamentos metodológicos aparentemente simples, mas que nos levam à profundidade da vivência e reconhecimento das dimensões êmicas do fazer musical. Ainda, reconhecendo que tais questões são apenas parte do processo e demonstrando uma ênfase nos porquês das atividades sociomusicais, Seeger (2015) proporciona uma visão que vai além da descrição dos fenômenos musicais, na direção de uma etnografia musical centrada na performance e com dimensões mais reflexivas/explicativas.

As etnografias de Turino (2008a, 2008b, 2008c, 2010) em torno da música Andina, 
Latino Americana e do sul da África, bem como suas inclinações teóricas para a semiótica da música e das relações entre música e política constituem a base de suas reflexões sobre performance musical. Sua contribuição mais facilmente perceptível na literatura etnomusicológica diz respeito às categorias de performance que englobam as práticas musicais participatórias e de apresentação, bem como suas relações com as práticas de gravação (subdivididas em música gravada com base em expectativas sobre performances ao vivo e música gravada com base em manipulação sonora em estúdio).

A partir de uma perspectiva interativa da performance, entendendo-a como um campo de múltiplos significados emergentes, Turino (2008a, 2008b, 2008c, 2010) aborda as práticas musicais como elementos centrais para o entendimento de dimensões mais amplas da sociedade, como identidade, diáspora, etnicidade, política, nacionalismo, cosmopolitismo, entre outras, que também contribuem para a compreensão das práticas e significados musicais. Nessa perspectiva investigativa cíclica, o entendimento da performance implica a compreensão dos significados construídos durante o processo interativo.

Essas perspectivas brevemente apresentadas sobre performance musical têm exercido significativa influência nas investigações musicais brasileiras. As abordagens mais amplas dos estudos da performance têm se articulado às perspectivas etnomusicológicas na construção de formas de olhar para os fenômenos musicais da cultura popular. Diante disso, discuto a seguir os principais paradigmas percebidos na análise de estudos etnomusicológicos sobre a cultura popular no Brasil.

\section{A performance musical da cultura popular em estudos etnomusicológicos brasileiros}

Na busca por compreender as principais perspectivas etnomusicológicas brasileiras sobre a performance musical da cultura popular, empreendi uma ampla pesquisa bibliográfica em teses e dissertações em Programas de Pós-Graduação em Artes/Música no Brasil, a partir de 1998. A limitação da busca às teses e dissertações foi definida porque tais materiais se configuram como representantes das principais linhas de pesquisa envolvendo a música da cultura popular no território nacional. O ano de 1998 foi definido como ponto de partida por ser o primeiro ano em que há registro de trabalhos etnomusicológicos em Programa de Pós-Graduação em Música nos relatórios oficiais dos programas no Brasil.

Para realizar as buscas dos materiais, tomei como bases de dados o Banco de Teses e Dissertações da Capes [BTDC] e as Bibliotecas Digitais de Teses e Dissertações das Instituições de Ensino Superior Brasileiras. Ainda, foram utilizados, como índices de publicações, os relatórios dos Programas de Pós-Graduação em Artes/Música apresentados à Capes e publicados como cadernos de indicadores, para posterior busca nos sites das Bibliotecas Digitais das IES.

Foram coletados todos os trabalhos disponíveis on-line em sites oficiais e mantidos os que apresentassem universos, metodologias e/ou dimensões epistemológicas próximas à etnomusicologia, totalizando 150 documentos. Posteriormente, foram incluídos na revisão apenas os trabalhos de cunho etnográfico que apresentassem informações sobre as práticas musicais de grupos de cultura popular. Cabe ressaltar que informações tangenciais às práticas, como artefatos culturais [instrumentos musicais] e indivíduos responsáveis pela prática [mestres e outros personagens], foram levadas em consideração nos critérios de inclusão. Ainda, aqui não estão elencados todos os trabalhos analisados, mas apenas as características gerais percebidas e alguns são citados como exemplos.

Embora as etnografias apresentem perspectivas teóricas fortemente ligadas às necessidades investigativas de cada universo e a consequente diversidade de posicionamentos 
pareça inevitável, foi possível perceber alguns direcionamentos mais recorrentes que possibilitaram compreender como a performance tem sido pensada no trato das práticas musicais da cultura popular no Brasil. A partir de correntes teóricas mais amplas sobre performance, como as perspectivas ritual, artística, comunicativa e sociointerativa, as etnografias apresentam dimensões transversais que acredito representarem de forma significativa sua produção. Nesse sentido, os posicionamentos teóricos são refletidos a partir das perspectivas pelas quais a performance é pensada diante dos contextos investigados, no intento de compreender como ela é caracterizada na literatura.

O termo performance é bastante recorrente, mas seu tratamento teórico não segue o mesmo padrão, uma vez que sua utilização é muitas vezes relacionada às referências mais generalizadas do desempenho e da prática musical. Assim, destaco aqui as perspectivas presentes em trabalhos que se preocuparam, de forma mais clara, em definir posicionamentos conceituais e epistemológicos em relação à performance musical.

Partindo da premissa básica e consensual na literatura de que performance musical não se restringe aos fenômenos acústicos, os trabalhos analisados apresentam três dimensões da performance que considero suficientes para compreender seus posicionamentos frente aos contextos estudados. As dimensões performáticas reflexivas, generativas e de resistência são, portanto, consideradas aqui como elementares para compreender o lócus epistemológico e as perspectivas conceituais das pesquisas analisadas.

\section{A performance reflexiva}

Partindo da visão de que as práticas musicais se constituem como uma das formas expressivas de cultura, a perspectiva da performance reflexiva apresentada nas teses e dissertações investigadas entende tais práticas como fenômenos integradores de comportamentos, significados, experiências e outros elementos que constituem a existência das comunidades culturais. Nesse sentido, a performance musical é entendida prioritariamente como um modo de expressão e comunicação, refletindo as características socioculturais das manifestações estudadas. Ainda, o foco na expressão não significa que os trabalhos não compreendam as dimensões generativas da performance musical em seus contextos, mas representa abordagens que levam a reflexividade como principal elemento de análise e compreensão da música como fenômeno sociocultural.

Queiroz (2005), ao investigar a música dos Catopês em Montes Claros/MG, entende a performance como um sistema comportamental, distintamente estilizado como fenômeno sociocultural, que reúne na música os elementos característicos da cultura, particularizando seu contexto e integrando dimensões simbólicas e estético-estruturais. Em caminhos semelhantes se encontram os trabalhos de Maia (2008), Giordani (2009), Medeiros (2012), Bastos (2010) e Vasconcelos (2010), entre outros.

Os trabalhos apresentam a forte influência da perspectiva antropológica de Victor Turner sobre performance e antropologia da experiência (TURNER, 1988, 2005) e das perspectivas etnomusicológicas do estudo que integra som e contexto, baseadas em Béhague (1984). No processo de reflexão e organização das experiências, que são concluídas pela performance, as práticas musicais são sempre compreendidas a partir de perspectivas contextuais, como evento e como processo, englobando dimensões sonoras, comportamentais, simbólicas e interativas. Assim, entendendo música como cultura (MERRIAM, 1964) e sua prática como uma forma de viver experiências socioculturais, a performance musical, na perspectiva da reflexividade, representa a possibilidade de compreender uma comunidade cultural a partir dela, um de seus extratos mais bem definidos e recorrentes. 
Vasconcelos (2010), ao estudar a relação entre música e ritual nas festas públicas do Candomblé Queto na Baixada Santista, destaca que ritual e música se articulam em performance, gerando "exteriorizações" de conteúdos compostos de significados importantes para a vida religiosa. A expressão e completude das experiências se dá através das performances, compreendidas como um conjunto de atos carregados de significados, revelando estruturas, categorizações, contradições, concepções e normas.

A partir dessas perspectivas a performance é apresentada como um importante aspecto cultural para a compreensão das práticas humanas. A característica reflexiva da performance evidencia, por meio dessas abordagens, uma prática esteticamente orientada de posicionamentos, percepções e expressões da realidade. Nesse sentido, as performances musicais de grupos da cultura popular são entendidas como possibilidades de acessar as dimensões expressivas da cultura.

\section{A performance generativa}

Influenciadas direta ou indiretamente pela abordagem da construção social da realidade (BERGER; LUCKMANN, 1991), algumas etnografias destacam a perspectiva de que a performance musical se constitui como momento e espaço de construção de significados, realidades e interações, característica tão importante quanto sua ação reflexiva da cultura. Nessa perspectiva, as práticas musicais são entendidas e destacadas como demarcadoras de territórios, geradora de identidades, produtoras de conhecimento etc.

Giesbrecht (2011), em sua etnografia sobre grupos de cultura popular de Campinas/ SP, defende que a performance em estilo participativo promove a incorporação e reapropriação de uma memória cultural negra da cidade. Através da organização da memória coletiva e da geração de laços comunitários, a performance engendra grupos sociais em torno de práticas, experiências, sentimentos, ideais e significados compartilhados.

Em trabalhos anteriores (RIBEIRO, 2011, 2013, 2017a, 2017b), tenho defendido a ideia de que performance musical, além de expressar, também pode negar, confirmar ou subverter dimensões socioculturais das quais faz parte e com os quais interage. Embora algumas reflexões teóricas produzidas tendam a ser mais ligadas às características expressivas da performance, é possível notar, através dos relatos etnográficos produzidos, como a performance gera e organiza a prática ritual, o sentimento de pertencimento e promove a interação social em diversas ordens.

Cabe destacar, ainda, que a performance participativa (TURINO, 2008a) tem sido compreendida como maior foco de análise em trabalhos que buscam compreender suas dimensões generativas. Os posicionamentos de que a performance musical nos grupos de cultura popular engendra pertencimentos histórico-culturais (GIESBRECHT, 2011; AUTOR), constrói identidades (STEIN, 2009), gerencia ritos (ROSA, 2005) e define territórios (PRASS, 2009), entre outras possibilidades, estão baseados na esfera da participação e da interação social. Embora se reconheça que performances de apresentação (TURINO, 2008a) também possuam sua dimensão participativa, as etnografias têm lhes dado menor destaque em virtude das características dos grupos estudados.

\section{A performance de resistência}

Os grupos de cultura popular são comumente descritos como comunidades subalternas. Nessa conjuntura, suas performances têm sido compreendidas como um dos principais meios para mediar conflitos e promover lutas e resistências diante das situações opres- 
sivas a que muitas vezes são submetidos. As performances de resistência podem ser compreendidas como um tipo distinto de prática que envolve suas dimensões reflexivas e generativas na direção de aspectos socioculturais específicos. Portanto, uma abordagem que compreenda a música nesta perspectiva tem como foco as relações entre o caráter reflexivo e generativo da performance musical na produção de discursos de luta, buscando empoderamento dos grupos e a mudança de conceitos e comportamentos socioculturais.

Rosa (2009), partindo do contexto do Candomblé da Nação Xambá em Olinda/PE, destaca a performance musical como reflexiva das diferenças de gênero, pois resulta de processos de aprendizagem diferenciados para meninos e meninas, intimamente ligados ao trabalho doméstico. Adicionalmente, as reflexões críticas de Rosa (2009) reconhecem a dimensão generativa da performance na produção de conceitos e comportamentos em relação ao gênero. A autora discute, a partir da atuação das mulheres e outros agentes no contexto investigado, como a performance pode ser pensada como instrumento de ressignificação dos discursos sobre gênero e, consequentemente, como veículo de empoderamento.

Prass (2009) e Stein (2009) também destacam a dimensão aguerrida da performance ao ponto em que a compreendem como instrumento político em sua condição de ação aliada a diversas práticas sensoriais. Assim, estando no plano das experiências, a performance lida com emoções, evoca sentimentos e converte encontros potencialmente perigosos em representações, mas ainda assim exerce sua luta (PRASS, 2009; ROSA, 2009; STEIN, 2009).

Diante dessas perspectivas, entendo que dimensões performativas estão presentes na performance de resistência, ainda que indiretamente. O caráter performativo, nos termos de Austin (1975), nos faz perceber a performance como agente produtora de discursos e sentidos ao mesmo tempo em que possibilita questioná-los e ressignificá-los. O trabalho de Rosa (2009), por exemplo, se aproxima da teoria de Austin (1975) a partir das perspectivas de Butler $(2011,2013)$ ao compreender as relações entre gênero, música, corpo e sexualidade.

Enfim, as características da performance de resistência engloba as possibilidades de ação social e política por meio das práticas musicais. Nesse sentido, os grupos de cultura popular são entendidos como agentes potenciais de transformação, apresentando fortes condições de performatividade, de empoderamento, de questionamento e de reordenação de suas relações com outros setores da sociedade.

\section{Considerações finais}

A partir das características entendidas como mais frequentes na literatura analisada é possível notar um contexto epistemológico bem definido sobre performance nos estudos sobre a música da cultura popular no campo da etnomusicologia. Entendo que tais características são resultantes das bases construídas a partir das articulações entre os estudos da performance e os estudos etnomusicológicos sobre performance musical, pensando a música como um processo social que envolve uma diversidade de aspectos para além das dimensões sonoras. Diante dessa conjuntura, defendo que as etnografias analisadas evidenciam bases epistemológicas dos estudos da performance que têm orientado as perspectivas teórico-metodológicas e gerado paradigmas etnomusicológicos sobre a performance musical na cultura popular no contexto brasileiro.

As abordagens teóricas que pensam a performance como reflexiva, generativa e de resistência podem ser pensadas como principais paradigmas etnomusicológicos expressos na literatura estudada. Acredito que elas apontam para uma articulação dos aspectos performáticos pensados desde os anos 1960, mas em constante ressignificação diante das necessidades interpretativas de cada contexto cultural estudado. Tais abordagens reforçam 
principalmente as perspectivas do construcionismo social, da performatividade e da interatividade simbólico-social.

Perspectivas reflexivas da performance parecem ligadas ao processo de compreensão das dimensões simbólicas em interação coletiva, possibilitando a compreensão dos fenômenos a partir dos indivíduos produtores de sua música. Aspectos generativos da performance articulam principalmente as perspectivas do construcionismo musical, evidenciando abordagens dialéticas sobre as práticas musicais da cultura popular. Dando importância a todos os sujeitos como agentes na produção da música, as perspectivas generativas também se aproximam de abordagens sobre a performance participativa. Por fim, perspectivas que evidenciam a performance de resistência reforçam posicionamentos característicos da performatividade, destacando elementos performáticos de ação social.

Como já destacado, tais paradigmas não se apresentam de forma isolada na literatura estudada, mas estão presentes de forma diluída e transversal, com distintos graus de evidência. Entretanto, acredito que eles sejam importantes para reflexões sobre a produção de conhecimento sobre performance musical, envolvendo dimensões epistemológicas e metodológicas. Tais paradigmas representam formas de olhar que direcionam nossa produção de informações em campo, nossas análises e interpretações. Diante disso, este trabalho não pretende esgotar o assunto e tampouco apresentar perspectivas fechadas sobre a produção de conhecimento sobre a música da cultura popular. O que se espera, entretanto, é que se tenha lançado algumas luzes em um campo de estudos ainda pouco iluminado diante de diversas necessidades interpretativas das complexas realidades das práticas musicais.

\section{Referências}

ABRAHAMS, Roger D. Everyday life: a poetics of vernacular practices. Philadelphia: University of Pennsylvania Press, 2011.

AUSTIN, John Langshaw. How to do things with words. Cambridge: Harvard University Press, 1975.

BASTOS, Juliana Carla. A performance musical do Clube do Choro da Paraíba. 2010. 125f. Dissertação (Mestrado em Música) - Universidade Federal da Paraíba, João Pessoa, 2010.

BAUMAN, Richard. Folklore, cultural performances, and popular entertainments: a communications-centered handbook. New York: Oxford University Press, 1992.

. Fundamentos da performance. Sociedade e Estado, v. 29, n. 3, p. 727-746, dez. 2014.

1975.

. Verbal Art as Performance. American Anthropologist, v. 77, n. 2, p. 290-311,

BAUMAN, Richard ; BRIGGS, Charles. Poética e Performance como perspectivas críticas sobre a linguagem e a vida social. Ilha Revista de Antropologia, v. 8, n. 1,2, p. 185229, jan. 2006.

BÉHAGUE, Gerard. Performance practice. Westport: Greenwood Press, 1984.

. Review of Why Suya Sing. A Musical Anthropology of an Amazonian People. Latin American Music Review, v. 9, n. 2, p. 260-272, 1988.

BERGER, Peter L.; LUCKMANN, Thomas. A construção social da realidade: tratado de sociologia do conhecimento. Rio de Janeiro: Vozes, 1991. 
BLACKING, John. The study of man as music-maker. In: BLACKING, John; KEALIINOHOMOKO, Joann W. The Performing Arts: Music and Dance. Paris, New York: Walter de Gruyter, 1979.

BLAU, Jnan. Transcultural Music Review. More than "just” music: four performative topoi, the phish phenomenon, and the power of music in/and performance, v. 13, n. SI$B E$, 2009. Disponível em: <http://www.sibetrans.com/trans/trans13/art02.htm>. Acesso em: 12 set. 2010.

BORBA, Rodrigo. A linguagem importa? Sobre performance, performatividade e peregrinações conceituais. Cadernos Pagu, n. 43, p. 441-474, dez. 2014.

BUCHANAN, Donna A. Soundscapes from the Americas: ethnomusicological essays on the power, poetics, and ontology of performance. Burlington: Ashgate Publishing, Ltd., 2014.

BUTLER, Judith. Bodies that matter: on the discursive limits of sex. New York: Routledge, 2011.

. Excitable speech: a politics of the performative. New York: Routledge, 2013.

CARLSON, Marvin A. Performance: uma introdução crítica. Belo Horizonte: Editora UFMG, 2010.

DAWSEY, John C. O teatro dos "bóias-frias”: repensando a antropologia da performance. Horizontes Antropológicos, v. 11, n. 24, p. 15-34, dez. 2005.

. Sismologia da performance: ritual, drama e play na teoria antropológica. Revista de Antropologia, v. 50, n. 2, p. 527-570, dez. 2007.

. Turner, Benjamin e Antropologia da Performance: O lugar olhado (e ouvido) das coisas. CAMPOS - Revista de Antropologia Social, v. 7, n. 2, 2006. Disponível em: < http:// ojs.c3sl.ufpr.br/ojs2/index.php/campos/article/view/7322>. Acesso em: 2 nov. 2015.

FELD, Steven. Sound and sentiment: birds, weeping, poetics, and song in Kaluli expression. 3. ed. Durhan, London: Duke University Press, 2012.

FERREIRA, Francirosy. Pensar/fazer: uma antropologia da performance. Conception, v. 1, n. 1, dez. 2012. Disponível em: <http://www.publionline.iar.unicamp.br/index.php/ ppgac/article/view/55>. Acesso em: 5 out. 2014.

GEERTZ, Clifford. Local knowledge: further essays in interpretive anthropology. New York: Basic Books, 2008. . The interpretation of cultures: selected essays. New York: Basic Books, 1973.

GIORDANI, Ary. Mbaraka: metonímia musical Mbya. 2009. 179f. Dissertação (Mestrado em Música) - Universidade Federal do Paraná, Curitiba, 2009.

GOFFMAN, Erving. The presentation of self in everyday life. Harmondsworth: Penguin, 1990.

HERNDON, Marcia. Review of Performance Practice: Ethnomusicological Perspectives, Gerard Béhague. Ethnomusicology, v. 30, n. 2, p. 346-347, 1986.

HYMES, Dell. Breakthrough into performance. In: BEM-AMOS, Dan; GOLDSTEIN, Kenneth S. Folklore: performance and communication. Mouton: The Hague, The Ne- 
therlands, 1975. p. 11-74.

LANGDON, Esther Jean. Performance e sua diversidade como paradigma analítico: a contribuição da abordagem de Bauman e Briggs. Antropologia em primeira mão, n. Programa de Pós Graduação em Antropologia Social, UFSC, p. 5-26, 2007.

LUCAS, Maria Elizabeth. Apresentação. Horizontes Antropológicos, v. 11, n. 24, p. 7-11, dez. 2005.

MERRIAM, Alan P. The anthropology of music. Northwestern University Press: Evanston, Illinois, 1964.

MORÍN, José R. L. The Legacy of Américo Paredes. Colege Station: Texas A\&M University Press, 2006.

PIMENTEL, Danieli dos Santos; FARES, Josebel Akel. A performance em Paul Zumthor. In: SEMANA DE EXTENSÃO, PESQUISA E PÓS-GRADUAÇÃO - SEPESQ, 10, 2014, Porto Alegre. Porto Alegre: UniRitter, 2014. p. 1-8.

RIBEIRO, Fábio Henrique Gomes. A particularidade universal da performance musical: articulações entre o global e o local nos Catopês em Bocaiuva-MG. DEBATES (UNIRIO), v. 19, p. 112-135, 2017a. $268,2013$.

. Música e religião: interfaces na produção da performance. Opus, v. 19. p. 243-

. Performance Musical dos Ternos de Catopês de Bocaiuva - MG. 2011. F?. Dissertação (Mestrado em Música) - Universidade Federal da Paraíba, João Pessoa, 2011.

. Performance musical na cultura popular contemporânea de João Pessoa. 2017. ?F. Tese (Doutorado em Música) - Universidade Federal da Paraíba, João Pessoa, 2017b.

ROSA, Laila. As juremeiras da nação Xamba (Olinda, PE): mulheres, religião, música e poder. 2009. ?F. Tese (Doutorado em Música) - Universidade Federal da Bahia, Salvador, 2009.

ROYCE, Anya Peterson. Anthropology of the performing arts: artistry, virtuosity, and interpretation in cross-cultural perspective. New York: Rowman Altamira, 2004.

SCHECHNER, Richard. Between theater and anthropology. Philadelphia: University of Pennsylvania Press, 1989.

. Performance studies: an introduction. 2. ed. New York: Routledge, 2006.

. Performance theory. New York: Routledge, 2003.

. The future of ritual. New York: Routledge, 1995.

SCHECHNER, Richard et al. Special Issue on Performance Studies. Rupkatha Journal on Interdisciplinary Studies in Humanities. 2. ed. Kolkata: Rupkatha, 2013.

SEEGER, Anthony. Por que cantam os Kisêdjê. São Paulo: Cosac Nayf, 2015.

SILVA, Rubens Alves Da. Entre "artes” e "ciências": a noção de performance e drama no campo das ciências sociais. Horizontes Antropológicos, v. 11, n. 24, p. 35-65, dez. 2005.

SINGER, Milton. Traditional India: Structure \& Change. Philadelphia: American Folklore Society, 1959. 
TURINO, Thomas. Moving Away from Silence: Music of the Peruvian Altiplano and the Experience of Urban Migration. Chicago: University of Chicago Press, 2010.

Press, 2008a.

. Music as social life: the politics of participation. Chicago: University of Chicago . Music in the Andes: experiencing music, expressing culture. New York, Oxford: Oxford University Press, 2008b.

. Nationalists, cosmopolitans, and popular music in Zimbabwe. Chicago: University of Chicago Press, 2008c.

TURNER, Victor W. Dewey, Dilthey e Drama: um ensaio em antropologia da experiência (primeira parte), de Victor Turner. Tradução Herbert Rodrigues. Cadernos de Campo, São Paulo, v. 13, n. 13, p. 177-185, mar. 2005.

. From ritual to theatre: the human seriousness of play. New York: PAJ, 1996.

. The anthropology of performance. New York: PAJ, 1988.

. The ritual process. New Brunswick: Transaction, 2009.

VOLPE, Maria Alice. O legado de Gerard Béhague (1937-2005). Revista Brasileira de Música, PPGM/UFRJ, v. 23, n. 1, p. 167-173, 2010.

ZUMTHOR, Paul. Performance, recepção, leitura. Tradução Jerusa Pires Ferreira; Suely Fenerich. São Paulo: Cosac Naify, 2007.

Fábio Henrique Gomes Ribeiro: Professor Adjunto do Departamento de Educação Musical da Universidade Federal da Paraíba, mestre e doutor em Música (Etnomusicologia) pela mesma instituição. 